\title{
Ewe-lamb bonding behaviours at birth are affected by maternal undernutrition in pregnancy
}

\author{
Cathy M. Dwyer ${ }^{1}$, Alistair B. Lawrence ${ }^{1}$, Stephen C. Bishop ${ }^{2}$ and Mitch Lewis ${ }^{1}$ \\ ${ }^{1}$ Animal Biology Division, SAC, West Mains Road, Edinburgh EH9 3JG, Scotland, UK \\ ${ }^{2}$ Roslin Institute, Roslin, Midlothian EH25 9PS, Scotland, UK
}

(Received 12 November 2001 - Revised 27 July 2002 - Accepted 22 August 2002)

\begin{abstract}
Maternal undernutrition in pregnancy results in low birth-weights and impaired postnatal survival in sheep. Largely anecdotal evidence suggests that the expression of appropriate maternal and neonate behaviours may also be disrupted by undernutrition. In the present study, we investigated the effect of a moderate $(35 \%)$ reduction in ewe nutritional intake in pregnancy on the expression of ewe-lamb bonding behaviours in primiparous Scottish Blackface ewes. Lowintake (L) ewes had significantly higher plasma progesterone than high-intake $(\mathrm{H})$ ewes from mid-gestation onwards (e.g. plasma progesterone at 20 weeks (ng/ml): H 15.72, L 22.38, SED $1.80, P<0.001)$, and a lower oestradiol: progesterone value than $\mathrm{H}$ ewes at delivery $(\mathrm{H} 0.46$, L 0.35 , SED $0.05, P<0.05$ ). Lamb birth-weight was reduced in the $\mathrm{L}$ lambs compared with $\mathrm{H}$ lambs (mean body weight $(\mathrm{kg}): \mathrm{H} 3 \cdot 31$, L 3.00, SED $0 \cdot 14, P<0 \cdot 05)$, but the incidence of malpresentation at delivery was greater in L lambs. L ewes spent significantly less time licking their lambs than $\mathrm{H}$ ewes after delivery (time grooming in $2 \mathrm{~h}$ after birth (\%): $\mathrm{H} \mathrm{56 \cdot 12, \textrm {L }}$ 48.17, SED 2.639, $P<0 \cdot 01$ ) and were more aggressive towards the lambs. Lamb behaviours were not directly affected by maternal nutritional treatment, but lamb birth-weight had a significant effect on neonatal developmental progress. Low-birth-weight lambs were slower than heavier lambs to stand and sucked less frequently. In tests of maternal attachment to the lamb, $\mathrm{H}$ ewes received higher scores than $\mathrm{L}$ ewes at both $24 \mathrm{~h}$ after birth (ewes receiving high scores $(\%)$ : $\mathrm{H} 41 \cdot 3, \mathrm{~L} 21.4, P<0.05)$ and at $3 \mathrm{~d}$ postnatal. We conclude that even a moderate level of undernutrition impairs the attachment between ewes and lambs by affecting maternal behaviours expressed at birth. In addition, the results suggest that levels of nutrition resulting in a decrease in birth weight will affect neonatal lamb behavioural progress.
\end{abstract}

Food restriction: Pregnancy: Maternal behaviour: Neonate behaviour

Reproduction in the sheep is timed so that lamb birth and maternal lactation coincide with the best environmental conditions in the spring. For hill sheep, this means that they are pregnant during winter grazing and periods of undernutrition if supplementary feeding is absent or inadequate. Without supplementary feed, pregnant hill sheep may lose $85 \%$ of their subcutaneous fat during pregnancy and lactation (Russel et al. 1968). Maternal nutrition in pregnancy affects both lamb birth-weight (for reviews, see Mellor, 1983; Robinson et al. 1999) and the incidence of lamb mortality (Waterhouse et al. 1992; Kleeman et al. 1993; Hinch et al. 1996). Light-weight lambs, particularly of multiple litters, have higher incidences of deaths from exposure and starvation than heavy lambs (Scales et al. 1986). In addition, light lambs are at greater risk of hypothermia than heavy lambs (Moore et al. 1986;
Clarke et al. 1997) due to their larger relative surface area, reduced body reserves and reduced thermogenic capability of brown adipose tissue (Robinson \& Aitkin, 1985; Budge et al. 2000). Maternal undernutrition is also associated with a reduction in udder weight and mammary development (Mellor \& Murray, 1985; Mellor et al. 1987; Charismiadou et al. 2000), resulting in a reduced colostrum yield (Mellor \& Murray, 1985; Hall et al. 1992; O'Doherty \& Crosby, 1996) and total milk production (O'Doherty \& Crosby, 1996; Bizelis et al. 2000). In addition, maternal undernutrition is associated with a delayed onset of lactation (Mellor et al. 1987) and a lower milk secretion rate (Mellor et al. 1987; Hall et al. 1992).

Maternal undernutrition may also impair lamb survival by affecting the appropriate expression of maternal and neonate behaviours at birth associated with ewe-lamb 
bonding. Few studies have, however, considered the effects of nutrition on the behaviour of either ewe or lamb. A preliminary study (Thomson \& Thomson, 1949) suggested that undernourished ewes took longer to attend to their lambs, and a larger proportion showed 'perfunctory or casual' attentiveness in cleaning the lambs and allowing them to suck than in well-fed ewes. Few other studies have been carried out, although two largely descriptive studies suggest that undernourished mothers have 'inadequate mothering ability' (McDonald, 1962), and, in deer, were more likely to ignore, avoid and be aggressive to their young than well-fed mothers (Langenau \& Lerg, 1976). Low nutrition in the last 6 weeks of gestation is also reported to increase the number of desertions of twin lambs in comparison with well-fed Merino ewes (Putu et al. 1988). In addition, lambs born to undernourished ewes are described as lacking in vitality or being of low vigour (Thompson \& Thompson, 1949; Moore et al. 1986), although these terms are poorly defined. Some of the apparently poor maternal care, such as desertion, may therefore be attributable to lamb weakness and inability to follow, rather than a failure in maternal ability. Although these results suggest that maternal nutrition in pregnancy may affect the expression of both ewe and lamb behaviour, a quantitative study of the interactions between nutrition in pregnancy and subsequent mother-offspring behaviour is lacking.

The purpose of the present study was to quantify the effects of a reduced feed intake, throughout gestation, on the expression of maternal and neonate behaviours at parturition in Scottish hill sheep, and their consequences for ewe-lamb attachment. The high feed intake $(\mathrm{H})$ ewes were fed a level that were approximately equal to the estimated energy requirements for a gravid $50 \mathrm{~kg}$ ewe (Agriculture and Food Research Council, 1993), whereas the low feed intake (L) ewes received approximately $65 \%$ of the intake of $\mathrm{H}$ ewes. This level of nutritional restriction was designed to mimic what ewes may experience in a moderately poor winter. In addition to behavioural measures, maternal plasma oestradiol and progesterone concentrations were measured throughout gestation. Plasma oestradiol concentration in late gestation is correlated with the expression of maternal behaviours in sheep (Shipka \& Ford, 1991; Dwyer et al. 1999) and progesterone has also been implicated in the control of maternal behaviour in the sheep, particularly in reducing aggressive behaviours (Kendrick \& Keverne, 1991). Thus, nutrition may affect the expression of maternal behaviour directly through its actions on the hormonal regulators of maternal behaviour or by, for example, the competing motivations of hunger and the desire to express maternal behaviours or remain with the lamb.

\section{Materials and methods}

The entire protocol was reviewed and approved by the local experiments and ethics committee (Scottish Agricultural College, Edinburgh, Scotland, UK) and specific procedures were done under an Animal (Scientific Procedures) Act 1986 Project Licence granted by the Home Office.

\section{Animals}

Primiparous 2-year-old Scottish Blackface ewes were used in this study. Primiparous ewes were used to eliminate confounding the results by variations in previous maternal experience. The ewes used in the present study were sired by rams resulting from 7 years of divergent selection on an index to alter carcass composition resulting in two lines of animals. Approximately equal numbers of ewes from each selection line were used, and were known to differ in the relative amounts of fat to lean in the carcass. Ewes were synchronised in oestrous using progesterone sponges (Veramix, Upjohn Ltd, Crawley, Sussex, UK), and artificially inseminated with semen from one of five unselected, randomly chosen rams. Ewes were weighed and a measure of backfat (condition score on a scale of 0 (emaciated)-5 (very fat) was determined before conception and then at intervals of 2 weeks throughout gestation. A final weight and condition score were taken $3 \mathrm{~d}$ postpartum. Blood samples $(7 \mathrm{ml})$ were collected by jugular venepuncture between 10.00 and 12.00 hours at intervals of 2 weeks from week 4 after conception until week 20 , and at $3 \mathrm{~d}$ postpartum, in all lambed ewes. Plasma was separated by centrifugation and stored at $-70^{\circ} \mathrm{C}$ until assayed for $17 \beta$-oestradiol and progesterone concentration by radioimmunoassay. Additional blood samples were taken at intervals of 1 week over the last 6 weeks of gestation for determination of $\beta$-hydroxybutyrate, an indicator of maternal mobilisation of body reserves.

\section{Nutritional treatments}

Ewes were brought indoors to large straw-bedded pens in week 4 of gestation and randomly allocated to $\mathrm{H}$ or $\mathrm{L}$ (approximately $65 \%$ of the intake of $\mathrm{H}$ ewes nutritional treatment). Litter size was determined by ultrasonography at week 6 and nutritional intakes were adjusted by litter size as well as treatment group thereafter. Nutritional intakes were manipulated by controlling hay intake initially and then by managing concentrate intake (see Table 1 for daily intakes). Ewes were provided with unlimited fresh drinking water throughout. L ewes also received $10 \mathrm{~g}$ mineral supplement (Norvite Sheep, 305W; SCA Nutrition Ltd, Thirsk, Yorks., UK)/d from week 11 until they received concentrate feed to ensure that $\mathrm{L}$ ewes were not compromised for trace elements and vitamins compared with $\mathrm{H}$ ewes. Ewes were vaccinated with a clostridial vaccine (Heptavac- $P$ plus; Intervet Limited, Milton Keynes, Bucks., UK) in week 17. Ewes lambed in large straw-bedded pens $(7 \times 7 \mathrm{~m})$ in groups of $10-12$ animals.

\section{Lambing management}

In total, sixty-one ewes (thirty-two $\mathrm{H}$, twenty-nine $\mathrm{L}$ ) were recorded at lambing in the study, producing 117 lambs. There were eight single and seventeen twin pregnancies recorded in each treatment group, but seven and four triplet litters in the $\mathrm{H}$ and $\mathrm{L}$ groups respectively. Ewes lambed over a 2 -week period and were kept under $24 \mathrm{~h}$ surveillance during this time. In addition, a continuous videotape record 
Table 1. Daily intakes of hay and concentrates for ewes fed on either a high or low food intake from week 4 of pregnancy (Mean values)

\begin{tabular}{|c|c|c|c|c|c|c|c|c|c|c|c|c|c|c|c|c|c|c|}
\hline \multirow{4}{*}{$\begin{array}{l}\text { Time of } \\
\text { gestation } \\
\text { (weeks) }\end{array}$} & \multicolumn{9}{|c|}{ High-intake ewes† } & \multicolumn{9}{|c|}{ Low-intake ewes* $\ddagger$} \\
\hline & \multicolumn{3}{|c|}{ Single } & \multicolumn{3}{|c|}{ Twin } & \multicolumn{3}{|c|}{ Triplet } & \multicolumn{3}{|c|}{ Single } & \multicolumn{3}{|c|}{ Twin } & \multicolumn{3}{|c|}{ Triplet } \\
\hline & \multicolumn{2}{|c|}{ Food intake (kg/d) } & \multirow{2}{*}{$\begin{array}{l}\text { Energy } \\
\text { intake } \\
\text { (MJ } \\
\mathrm{ME} / \mathrm{d} \text { ) }\end{array}$} & \multicolumn{2}{|c|}{ Food intake (kg/d) } & \multirow{2}{*}{$\begin{array}{l}\text { Energy } \\
\text { intake } \\
\text { (MJ } \\
\mathrm{ME} / \mathrm{d} \text { ) }\end{array}$} & \multicolumn{2}{|c|}{ Food intake $(\mathrm{kg} / \mathrm{d})$} & \multirow{2}{*}{$\begin{array}{l}\text { Energy } \\
\text { intake } \\
\text { (MJ } \\
\mathrm{ME} / \mathrm{d})\end{array}$} & \multicolumn{2}{|c|}{ Food intake (kg/d) } & \multirow{2}{*}{$\begin{array}{l}\text { Energy } \\
\text { intake } \\
\text { (MJ } \\
\text { ME/d) }\end{array}$} & \multicolumn{2}{|c|}{ Food intake (kg/d) } & \multirow{2}{*}{$\begin{array}{l}\text { Energy } \\
\text { intake } \\
\text { (MJ } \\
\mathrm{ME} / \mathrm{d})\end{array}$} & \multicolumn{2}{|c|}{ Food intake (kg/d) } & \multirow{2}{*}{$\begin{array}{c}\text { Energy } \\
\text { intake } \\
\text { (MJ } \\
\mathrm{ME} / \mathrm{d})\end{array}$} \\
\hline & Hay§ & Concentrates\| & & Hay§ & Concentrates\| & & Hay§ & Concentrates\| & & Hay§ & Concentrates\| & & Hay§ & Concentrates\| & & Hay§ & Concentrates\| & \\
\hline $4-6$ & 0.80 & 0.00 & $5 \cdot 2$ & 0.80 & 0.00 & $5 \cdot 2$ & 0.80 & 0.00 & $5 \cdot 2$ & 0.70 & 0.00 & 4.5 & 0.70 & 0.00 & 4.5 & 0.70 & 0.00 & 4.5 \\
\hline $7-9$ & 1.20 & 0.00 & 7.8 & 1.20 & 0.00 & 7.8 & 1.20 & 0.00 & 7.8 & 0.70 & 0.00 & 4.5 & 0.70 & 0.00 & 4.5 & 0.70 & 0.00 & 4.5 \\
\hline 10 & 1.29 & 0.00 & 8.3 & 1.23 & 0.00 & 8.0 & 1.24 & 0.00 & 8.0 & 0.70 & 0.00 & 4.5 & 0.80 & 0.00 & $5 \cdot 2$ & 0.80 & 0.00 & $5 \cdot 2$ \\
\hline 11 & 1.48 & 0.00 & 9.6 & $1 \cdot 16$ & 0.20 & 9.7 & 1.38 & 0.20 & $11 \cdot 1$ & 0.80 & 0.00 & 5.2 & 0.90 & 0.00 & 5.8 & 0.90 & 0.00 & 5.8 \\
\hline 12 & 1.26 & 0.00 & 8.1 & 1.22 & 0.20 & 10.0 & 1.32 & 0.20 & 10.7 & 0.80 & 0.00 & $5 \cdot 2$ & 0.90 & 0.00 & 5.8 & 0.90 & 0.00 & 5.8 \\
\hline 13 & 1.32 & 0.20 & 10.7 & 1.17 & 0.30 & 10.8 & 1.26 & 0.30 & 11.4 & 0.80 & 0.00 & 5.2 & 0.90 & 0.00 & 5.8 & 1.38 & 0.10 & 8.5 \\
\hline 14 & 1.49 & 0.20 & 11.8 & 1.26 & 0.30 & 11.4 & 1.26 & 0.30 & 11.4 & 0.80 & 0.00 & 5.2 & 0.90 & 0.00 & 5.8 & 1.14 & 0.10 & 8.5 \\
\hline 15 & 1.33 & 0.20 & 10.8 & 1.20 & 0.60 & 14.2 & 1.26 & 0.70 & 15.7 & 1.21 & 0.00 & 7.8 & 1.18 & 0.10 & 8.7 & 1.11 & 0.20 & $9 \cdot 3$ \\
\hline $16-17$ & 0.0 & 0.40 & 12.9 & 0.0 & 0.75 & 15.8 & 0.0 & 0.80 & $16 \cdot 8$ & 0.0 & 0.0 & 7.8 & 0.0 & 0.20 & 9.8 & 0.0 & 0.30 & $10 \cdot 4$ \\
\hline 18-lambing & 0.0 & 0.40 & 12.9 & 0.0 & 0.75 & 15.8 & 0.0 & 0.80 & $16 \cdot 8$ & 0.0 & 0.20 & 10.0 & 0.0 & 0.50 & 13.0 & 0.0 & 0.60 & $13 \cdot 6$ \\
\hline
\end{tabular}


was made using eight cameras and a Panasonic eightchannel digital field switcher (WJ-FS20/B, Matsushita Communication Industrial, Yokohama, Japan). Ewes were accustomed to the presence of observers in the walkways between pens in the weeks before parturition, and were clearly identified by paint-brands to facilitate recognition on the videotapes.

As far as possible, ewes were allowed to give birth and care for their lambs unaided. However, lambing assistance was given if the ewe had failed to progress through a time schedule of events, i.e. $60 \mathrm{~min}$ after the appearance of fluids there was no appearance of parts of the lamb, and/or $120 \mathrm{~min}$ after parts of the lamb were seen at the vulva there was no other obvious progress being made. In all cases, intervention was kept to a minimum and mainly involved correcting lamb presentation before the ewe continued the birth process unaided. Assistance at delivery was scored as follows: no assistance, partial assistance (lamb presentation corrected, ewe delivered unaided), manual delivery (ewe assisted to deliver the lamb). Ewes that abandoned or rejected their lambs were placed in an individual pen with their lambs $60 \mathrm{~min}$ after birth and behavioural data for these animals were truncated at $60 \mathrm{~min}$.

Ewes and their lambs remained indoors, in the lambing pens, for the first $3 \mathrm{~d}$ after delivery. Multiple litters were reduced to two lambs at $24 \mathrm{~h}$ by removal of the smallest lambs, unless there were husbandry reasons for removing other lambs. Removed lambs were hand-reared, or fostered to a suitable non-trial ewe, and data for these animals are thus terminated at $24 \mathrm{~h}$ old. After $3 \mathrm{~d}$, ewes and lambs were moved outside to a 7.9 ha field.

\section{Data collection}

Behaviour at parturition. The overt length of labour (calculated from appearance of fluids until birth of last lamb), the interval between littermates and the degree of assistance required were recorded for all ewes. Lamb presentation at birth was also recorded as normal (both forelegs extended, with the nose lying along the legs) or one of a number of abnormal postures (one or both legs retracted, head back, backwards, breech or two or more lambs presented at the same time).

Data on maternal and neonate behaviour were collected from videotape during four observation periods in the 120 min after the birth of a lamb, using Observer datarecording software (Noldus et al. 2000). In addition, vocalisations of the ewe and lambs were collected live, using handheld Psion Workabouts (Psio PLC, London, UK) and Observer software. Data were collected for the first 120 min after the birth of each lamb as follows: the first $30 \mathrm{~min}$, followed by three $10 \mathrm{~min}$ periods, every $30 \mathrm{~min}$ over the following $90 \mathrm{~min}$. The definitions of ewe and lamb behaviours are as previously described (Dwyer \& Lawrence, 1998; Dwyer et al. 2001).

Behaviour over the first $3 d$. Lamb birth-weight and sex were recorded within $24 \mathrm{~h}$ of birth. Once lambs were dry, they were marked with the identification number of their mothers, and for birth order. Additional behavioural data were collected by scan sampling at intervals of $2 \mathrm{~h}$ for the first $3 \mathrm{~d}$ after parturition when ewes and lambs were kept indoors in the lambing pens. The posture, behaviour and distance between the ewe and her lamb(s) were recorded. Ewe and lamb behaviours were as defined at birth and, in addition, we recorded 'eating' (any behaviours where animals were seen at the feeder and chewing), 'investigatory behaviours' (nosing pen fixtures, animals other than the ewe or own lambs, substrates but not eating), 'ruminating' (characteristic movements of the jaw by adult ewes) and 'other' (all other behaviours which occurred at low frequency).

Ewes were given a maternal behaviour score at $24 \mathrm{~h}$ after birth on the basis of their response to the handling of their lambs on a scale from 1 (leaves lamb, does not return)-6 (remains within $1 \mathrm{~m}$ of lamb, makes physical contact with lamb) as previously described (after O'Connor et al. 1985; modified after Dwyer \& Lawrence, 1998). At $3 \mathrm{~d}$ after birth, ewes were given a second attachment score based on their response to a handler carrying the lambs slowly out of the home pen from 1 (no concern, does not follow the lambs from the home pen) -4 (follows lambs closely and leaves home pen).

\section{Radioimunoassays}

Oestradiol. Plasma oestradiol concentration was determined in duplicate in $500 \mu \mathrm{l}$ samples (after Mann et al. 1995). Samples were first extracted by addition of $2.5 \mathrm{ml}$ diethyl ether and separation of the ether layer. Samples were reconstituted in PBS-gel and assayed using Estradiol Maia radioimmunoassay kits (BioChem ImmunoSystems, Bologna, Italy). Briefly, the samples were incubated with ${ }^{125}$ I-labelled oestradiol tracer (Amersham International plc, Amersham, Bucks., UK) and rabbit antiserum at $37^{\circ} \mathrm{C}$ for $2 \mathrm{~h}$. The bound fraction was separated by magnetic sedimentation of the solid phase, and counted in a $\gamma$-scintillation counter. The inter- and intra-assay $\mathrm{CV}$ were 15.0 and $10.5 \%$ respectively.

Progesterone. Progesterone samples were determined in duplicate in $100 \mu \mathrm{l}$ samples (after McNeilly \& Fraser, 1987). Samples were incubated with rabbit antiserum (a gift from the Scottish Antibody Production Unit, Law Hospital, Carluke, Scotland, UK) and ${ }^{125}$ I-labelled tracer (Amersham International plc) for $4 \mathrm{~h}$ at $37^{\circ} \mathrm{C}$. A donkey anti-rabbit second antibody (a gift from the Scottish Antibody Production Unit) was added and tubes were incubated overnight at $4{ }^{\circ} \mathrm{C}$. The bound fraction was separated using a PEG and Triton $X$ separation solution and counted in a $\gamma$-counter. The inter- and intra-assay $\mathrm{CV}$ were 12.7 and $10.4 \%$ respectively.

\section{Statistical analysis}

Ewe behaviours were analysed as means for a $10 \mathrm{~min}$ period; the initial $30 \mathrm{~min}$ sample was incremented as $3 \times$ 10 min repeated samples. Behaviours that occurred infrequently, or were performed by relatively few animals, were analysed by $\chi^{2}$ tests. There were no interactions between the effects of selection line and nutrition; therefore, the effects of selection have been reported elsewhere (Dwyer et al. 2001). In the present analysis, selection line 
was fitted first and therefore excluded before the other effects were fitted. There were also no interactions of litter size $\times$ nutritional treatment for any physical or behavioural traits; therefore, the data from single, twin and triplet ewes could be combined in analysis. The sequential effects of litter size, lamb sex and nutritional treatment, $\times$ behaviour and $\times$ maternal physiology were analysed using the Residual Maximum Likelihood procedure (Patterson \& Thompson, 1971), given the relatively unbalanced nature of the data set. Skewed data were first normalised by square root transformations. For the analysis of ewe behaviours, treatment and litter size were fitted as fixed (block) effects in the model, length of labour and the interval between littermates were fitted as covariates. For the analysis of lamb behaviours treatment, litter size, lamb sex and the degree of assistance required were fitted as fixed effects, and ewe and sire identity were fitted as random effects. As lamb birth-weight did not have a linear effect on behaviours, lamb birth-weight was divided into categories based on the number of standard deviations above and below the mean birth weight (ranging from -3 to $+3 \mathrm{SD}$ ) and this was fitted as a fixed effect. No behavioural data were collected for lambs weighing $\geq-3$ sD below mean birth weight as all these lambs were stillborn. Length of labour was fitted as covariates in this analysis. The GenStat 5 statistics package (GenStat 5 Committee, 1993; Lawes Agricultural Trust, Rothamstead Experimental Station, UK) was used throughout. Where the data could not be normalised by transformation significant effects were determined by Kruskal-Wallis ANOVA.

For data collected by scan sampling over the first $3 \mathrm{~d}$ after birth, there were no significant trends with time; therefore, all data were pooled by ewe (ewe behaviours) or by lamb (lamb behaviours) for analysis. The effects of treatment, litter size and lamb sex were analysed by Residual Maximum Likelihood procedures. In the analysis of lamb behaviour, dam and sire identity were fitted as random effects.
Maternal plasma oestradiol, progesterone and $\beta$-hydroxybutyrate concentrations were analysed at each time point using Residual Maximum Likelihood statistics and fitting litter size and treatment as fixed effects.

\section{Results}

\section{Effects on ewe weight and condition score}

There was no significant difference between ewes in mean pre-conception body weight (H 50.37 (SE 0.84), L 49.29 (SE $0.99) \mathrm{kg}$ ) or mean condition score (H 3.59 (SE 0.04), L 3.60 (SE 0.06)). $\mathrm{H}$ ewes gained weight throughout their pregnancy (Fig. 1) and had a net (conceptus-free) increase in weight of $2.84 \mathrm{~kg}$ at parturition. L ewes maintained body weight for most of their pregnancy, showing an increase in weight only over the last 2 weeks, and had a net loss of $3.39 \mathrm{~kg}$ during gestation. $\mathrm{H}$ ewes were significantly heavier than $\mathrm{L}$ ewes at week 14 of gestation (Fig. 1, $P<0.05)$ and remained so for the rest of gestation $(P<0.001)$. Litter size significantly affected mean ewe weight only at week 20 (single 54.09 (SE 1.98), twin 57.87 (SE 1.19), multiple 62.80 (SE 2.95) kg, $P<0.01$ ). Ewes in both treatment groups lost condition during their pregnancy; however, the loss was greater in L ewes from week 10 of gestation (condition score loss: $\mathrm{H}-0.15$ (SE $0.06), \mathrm{L}-0.31$ (SE 0.05), $P<0.05$ ) until lambing time (condition score loss at lambing: $\mathrm{H}-0.77$ (SE 0.087), L -1.33 (SE 0.065), $P<0.001$ ).

\section{Ewe physiology during gestation}

The changes in ewe plasma oestradiol and progesterone concentration during gestation are shown in Fig. 2. There was no difference in pre-conception oestradiol concentration in ewes of either nutritional group until mid-gestation. L ewes had significantly higher plasma oestradiol at weeks 14 (Fig. 2(a), $P<0 \cdot 05)$ and $16(P<0 \cdot 05)$ of gestation but not at other times. Plasma progesterone was elevated in

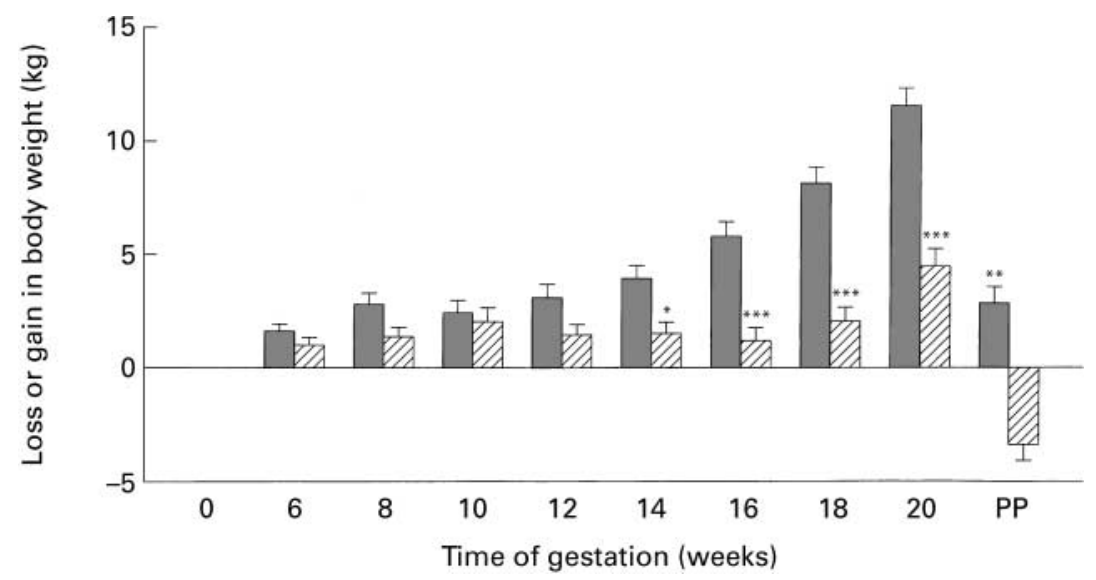

Fig. 1. Effect of high ( $\square, n$ 32) or low (包, $n$ 29) food intake in ewes on gravid maternal body weight over gestation and on conceptus-free maternal body weight at $72 \mathrm{~h}$ postpartum (PP; full term was $145 \mathrm{~d}$ ). Low-intake ewes were fed $65 \%$ of the intake of highintake ewes. For details of diets and procedures, see Table 1 and p. 124. Values are means with their standard errors shown by vertical bars. Mean values were significantly different from those of the high-intake ewes at each time of gestation: ${ }^{\star} P<0.05$, ${ }_{* \star \star} P<0.001$. 

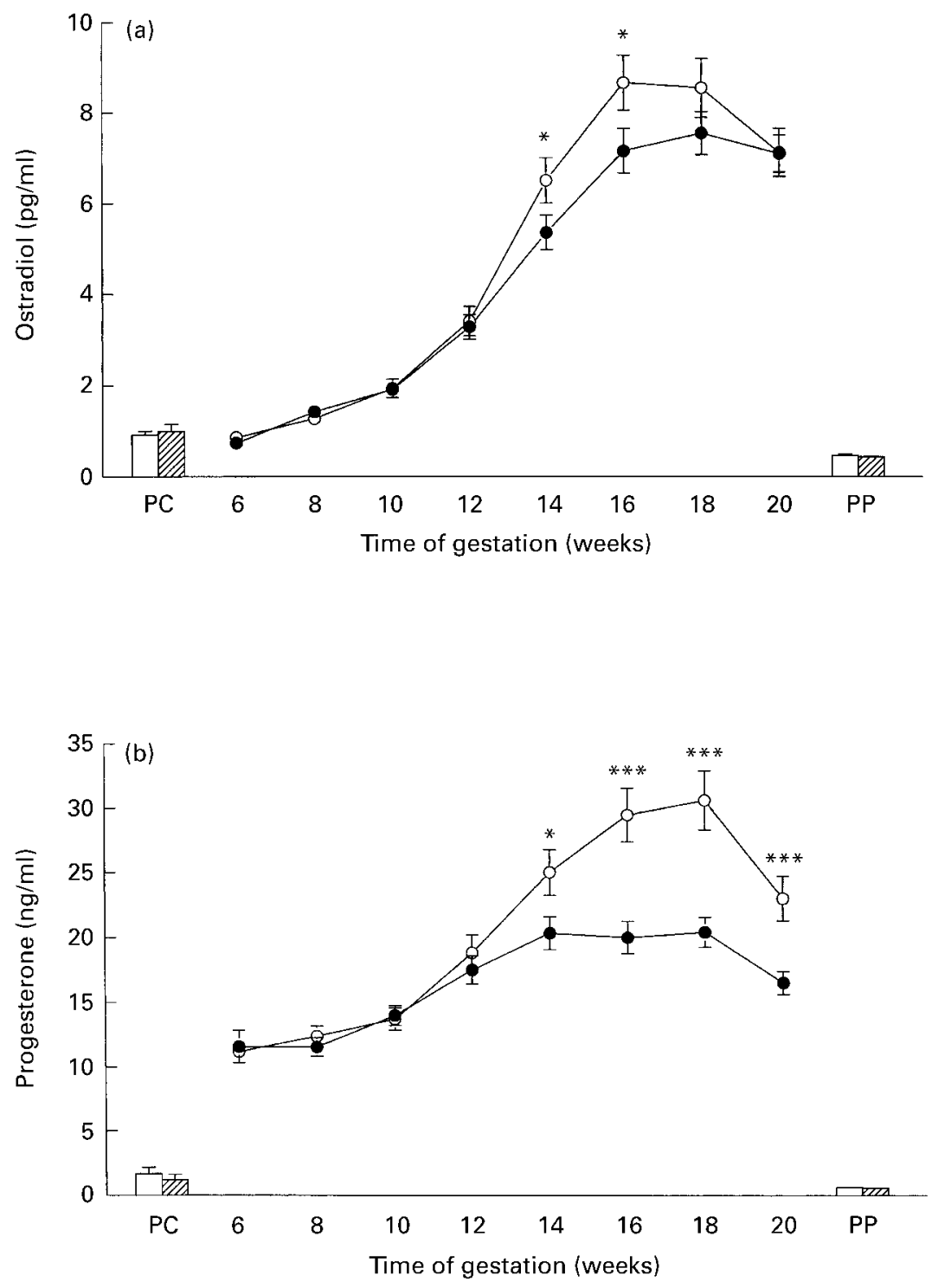

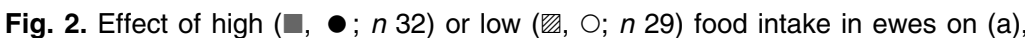
plasma oestradiol and (b), plasma progesterone and values pre-conception (PC) and $72 \mathrm{~h}$ postpartum (PP; full term was $145 \mathrm{~d}$ ). For details of diets and procedures, see Table 1 and p. 124. Values are means with their standard errors shown by vertical bars. Mean values were significantly different from those of the high-intake ewes at each time of gestation: ${ }^{\star} P<0.05,{ }^{\star \star \star} P<0.001$.

both groups at week 6 of gestation and increased in $\mathrm{L}$ ewes until week 18. This increase was smaller in $\mathrm{H}$ ewes resulting in a significantly higher progesterone concentration in $\mathrm{L}$ ewes at week 14 (Fig. 2(b), $P<0.05$ ) and this was maintained for the remainder of gestation $(P<0.001)$. As the temporal relationship between oestrogen and progesterone concentration may be important for the expression of maternal behaviour, we also calculated the value of this ratio at each time point. The value of the oestradiol: progesterone concentration ratio increased throughout gestation in both treatment groups. There were no significant differences between treatment groups until week 20 of gestation when the mean value of the ratio was higher in $\mathrm{H}$ ewes than L ewes ( $\mathrm{H} 0.456$, L $0 \cdot 352$, SED $0 \cdot 05, P<0 \cdot 05$ ).
The plasma concentration of $\beta$-hydroxybutyrate increased between weeks 15 and 18 in both treatment groups, and was maintained over the last 3 weeks of gestation. $\beta$-Hydroxybutyrate was significantly affected by litter size (single 0.299, twin 0.563, multiple $0.516 \mathrm{mmol} / \mathrm{l}$, SED $0.095, P<0.001)$ and by treatment group (H 0.351, L 0.569 mmol/1, SED 0.04, $P<0 \cdot 001$ ).

\section{Parturition results and lamb survival}

The effects of nutritional treatments on gestation length, length of labour, degree of birth difficulty and assistance required at delivery, lamb presentation and lamb birthweight are shown in Table 2. L ewes tended to have a longer gestation than $\mathrm{H}$ ewes by about $1 \mathrm{~d}$. There was no 
Table 2. Effects of nutritional treatments on the progress of parturition and lamb birth-weight* (Mean values)

\begin{tabular}{|c|c|c|c|c|}
\hline & High-intake ewes & Low-intake ewes & SED & Statistical significance of effect: $P$ \\
\hline Ewes $(n)$ & 32 & 29 & & \\
\hline Lambs $(n)$ & 63 & 54 & & \\
\hline Gestation length (d) & 143.5 & $144 \cdot 3$ & 0.42 & 0.074 \\
\hline Interval between twins (min) & $15 \cdot 1$ & 39.56 & $9 \cdot 37$ & $<0.05$ \\
\hline Lambs requiring assistance at delivery (\%) & $18 \cdot 8$ & $32 \cdot 7$ & & $0.08\left(\chi^{2} 3.07\right.$, df 1$)$ \\
\hline Lambs malpresented (\%) & $13 \cdot 11$ & $28 \cdot 8$ & & $<0.05\left(\chi^{2} 4.29\right.$, df 1$)$ \\
\hline Lamb birth-weight $(\mathrm{kg})$ & 3.31 & 3.00 & 0.14 & $<0.05$ \\
\hline \multicolumn{5}{|l|}{ Birth weights by litter: } \\
\hline Single & $4 \cdot 22$ & $3 \cdot 71$ & & \\
\hline Twin & $3 \cdot 20$ & 2.90 & & \\
\hline Triplet & 2.51 & 2.40 & & \\
\hline
\end{tabular}

${ }^{*}$ For details of diets and procedures, see Table 1 and p. 124.

significant difference between the two groups in the mean duration of labour (to the birth of the first lamb); however, $\mathrm{L}$ ewes had a significantly longer interval between the birth of the first and second lamb in a litter (Table 2, $P<0.05$ ). Lambs born to L ewes were more likely to be malpresented than lambs born to $\mathrm{H}$ ewes $(P<0 \cdot 05)$, and tended to require more intervention to be delivered $(P=0 \cdot 08)$. This was despite having a lower birth-weight than $\mathrm{H}$ lambs (Table 2, $P<0.05)$. Lamb presentation was affected by birth weight, as lambs born with one or both forelegs retracted were heavier, and breech or backwards presentations lighter, than correctly presented lambs (one leg back $4 \cdot 13$ (SE 0.23), two legs back 3.28 (SE 0.16), breech or backwards 2.42 (SE 0.25), correct 2.95 (SE 0.08) kg, $P<0.001$ ).

In total, $82.4 \%$ of lambs survived until weaning at 3 months, $12.6 \%$ of lambs died within $3 \mathrm{~d}$ of birth (before moving outside to the paddock) and a further $5.0 \%$ of lambs survived the postnatal period but died before weaning. Lambs that died within $3 \mathrm{~d}$ of birth were significantly lighter than lambs that survived $(P<0 \cdot 01)$; however, there was no significant difference in birth weight between lambs that died outside and lambs that survived (died within $3 \mathrm{~d}$ of birth $2 \cdot 1$ (SE $0 \cdot 17$ ), survived to $3 \mathrm{~d}$ but died before weaning $2 \cdot 89$ (SE 0.27), survived $3 \cdot 16$ (SE 0.08) $\mathrm{kg}$.

\section{Ewe behaviour at parturition}

Ewe grooming behaviour. There was no effect of nutritional treatment on the time to start grooming the lamb after delivery (H 1.53 (95\% CI 1.13, 2.06), L 2.12 (95\% CI $1.57,2.87)$ min, $P=0.58)$. There was no effect of litter size or lamb sex on grooming behaviour, but latency to groom was affected by birth difficulty. An increase in the amount of intervention required to deliver the lamb resulted in an increase in the time taken for the ewe to start to groom the lamb (no assistance 0.99 (95\% CI $0.58,1.66)$, partial assistance 1.52 (95\% CI $0.90,2.55)$, manual delivery $3.91(95 \%$ CI $2 \cdot 32,6.60) \mathrm{min}, P<0 \cdot 001)$.

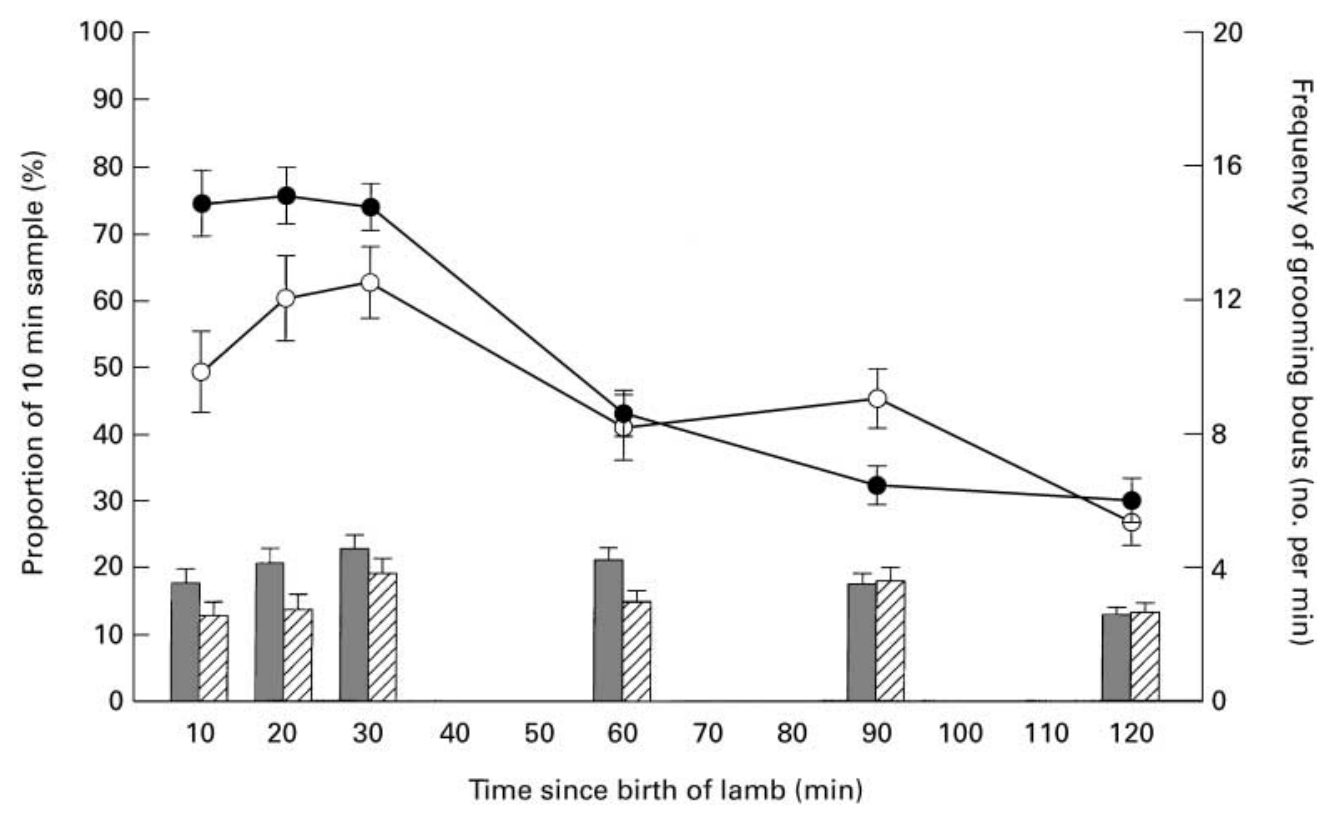

Fig. 3. Effect of high ( $n$ 32) or low ( $n$ 29) food intake in ewes on the proportion of each 10 min behaviour sample spent grooming the lamb (--, high intake; - - , low intake) and frequency of grooming bouts in the first $2 \mathrm{~h}$ after parturition ( $\square$, high intake; $\mathbb{Z}$, low intake). For details of diets and procedures, see Table 1 and p. 124. For details of significant effects, see p. 124. 
$\mathrm{H}$ ewes spent significantly more of the first $30 \mathrm{~min}$ after lamb birth grooming the lamb than $\mathrm{L}$ ewes (Fig. 3; $\mathrm{H}$ 74.67 , L 57.39 min, SED 6.20, $P<0 \cdot 01$ ). This appeared to be due to an increased number of grooming bouts by $\mathrm{H}$ ewes (Fig. 3; grooming frequency per min: H 4.06, L 3.03 , SED $0.75, P<0.05$ ) as the mean bout length did not differ between treatments. There was no significant difference between treatments in the proportion of time spent grooming ( $\mathrm{H} \mathrm{33.03,} \mathrm{L} \mathrm{37.51 \% ,} \mathrm{SED} \mathrm{3.42,} P=0.19$ ) over the last $90 \mathrm{~min}$ of the recording period (Fig. 3).

Ewe grooming behaviour was also affected by the length of labour, the interval between twins and by litter size. The proportion of time spent grooming in the first $30 \mathrm{~min}$ was reduced by a long labour (e.g. a $10 \mathrm{~min}$ increase in labour led to a $1.8 \%$ reduction in time spent grooming, $P<0.01$, which appeared to be due to a reduction in both frequency $(P=0.058)$ and mean bout length $(P<0 \cdot 05)$. Although labour had no effect on grooming behaviour in the later period, a long interval between twins did reduce the proportion of time spent grooming (e.g. a $10 \mathrm{~min}$ increase in twin interval resulted in a $2.00 \%$ decrease in maternal grooming, $P<0.001)$ by affecting both frequency $(P<0.05)$ and length of bouts $(P<0.01)$. An increase in litter size had no effect on the total amount of grooming behaviour expressed by the ewe, but there was a significant increase in the frequency of grooming bouts at both $30 \mathrm{~min}$ after birth (singles 1.89 , twins 3.03 , multiples 5.72 grooming bouts per min, SED $0.75, P<0.001$ ) and in the subsequent $90 \mathrm{~min}$ (singles $2 \cdot 06$, twins 3.04 , multiples 4.98 grooming bouts per min, SED $0.58, P<0 \cdot 001)$. This was associated with a corresponding decrease in bout length with increase in litter size (singles 7.3 (95\% CI 6.1, 8.8), twins 6.2 (95\% CI $5 \cdot 1,7 \cdot 4)$, multiples 5.0 (95\% CI $4 \cdot 1,6.0)$ s per bout, $P<0 \cdot 05)$.

Maternal rejection behaviours. There was no outright maternal rejection of lambs by any ewe. In total, 50.0\% of $\mathrm{H}$ ewes and $55.2 \%$ of $\mathrm{L}$ ewes expressed some rejection behaviours (withdrawal or avoidance, pushing, butting) in the first $30 \mathrm{~min}$ following lamb delivery, but only $6.7 \%$ of $\mathrm{H}$ ewes and $17.2 \%$ of $\mathrm{L}$ ewes continued to express these behaviours after $30 \mathrm{~min}$. There was no significant effect of treatment group on the number of ewes performing any lamb rejection behaviours, or the frequency that these behaviours were expressed. However, there was a tendency for L ewes to butt their lambs more frequently in the $90 \mathrm{~min}$ after delivery (H 0.00 (95\% CI 0.00, 0.01), L 0.05 (95\% CI $0.00,0.26)$ butts per h, $P=0.1)$.

Ewe feeding behaviour. L ewes tended to be more likely to eat during the first $30 \mathrm{~min}$ after the birth of their lambs (L 42.9, H 22.6\% ewes seen eating, $\chi^{2} 2 \cdot 77$, df 1 , $P=0.096)$. L ewes also spent significantly more time eating in the first hour after the birth of their lambs than $\mathrm{H}$ ewes (median values: $\mathrm{H} 0.30$ (interquartile range $0 \cdot 00-3.58$ ), L 2.56 (interquartile range 0.64-17.46) \% time spent eating, $\chi^{2}$ Kruskal-Wallis H 5.95, df $1, P<0 \cdot 05$ ).

\section{Neonatal lamb behavioural progress}

There were no direct effects of nutritional treatment on the time taken by the lamb to reach any of the developmental

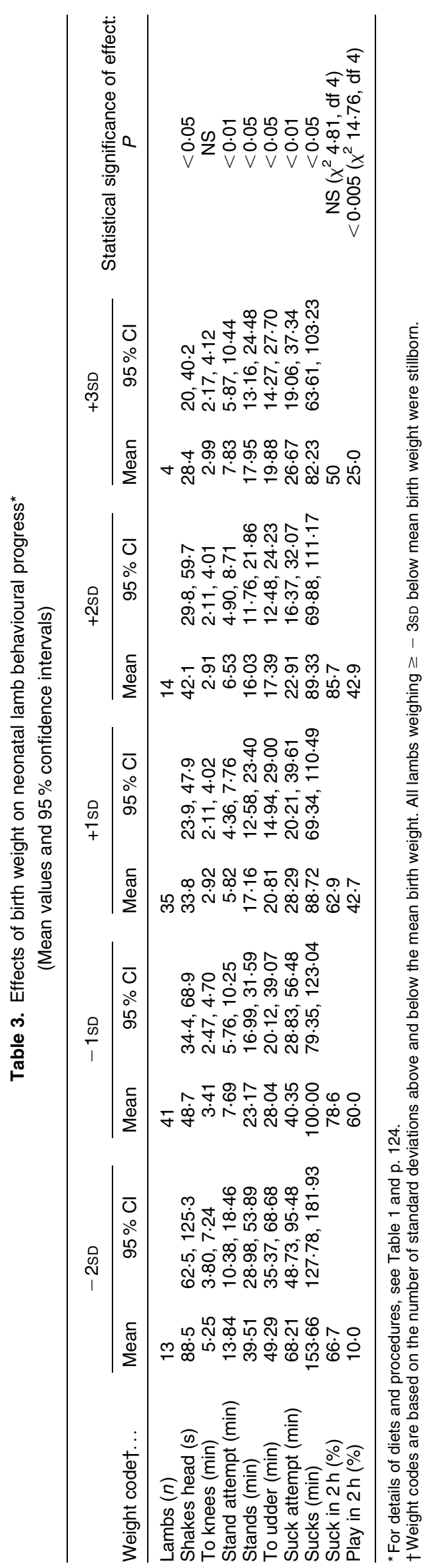



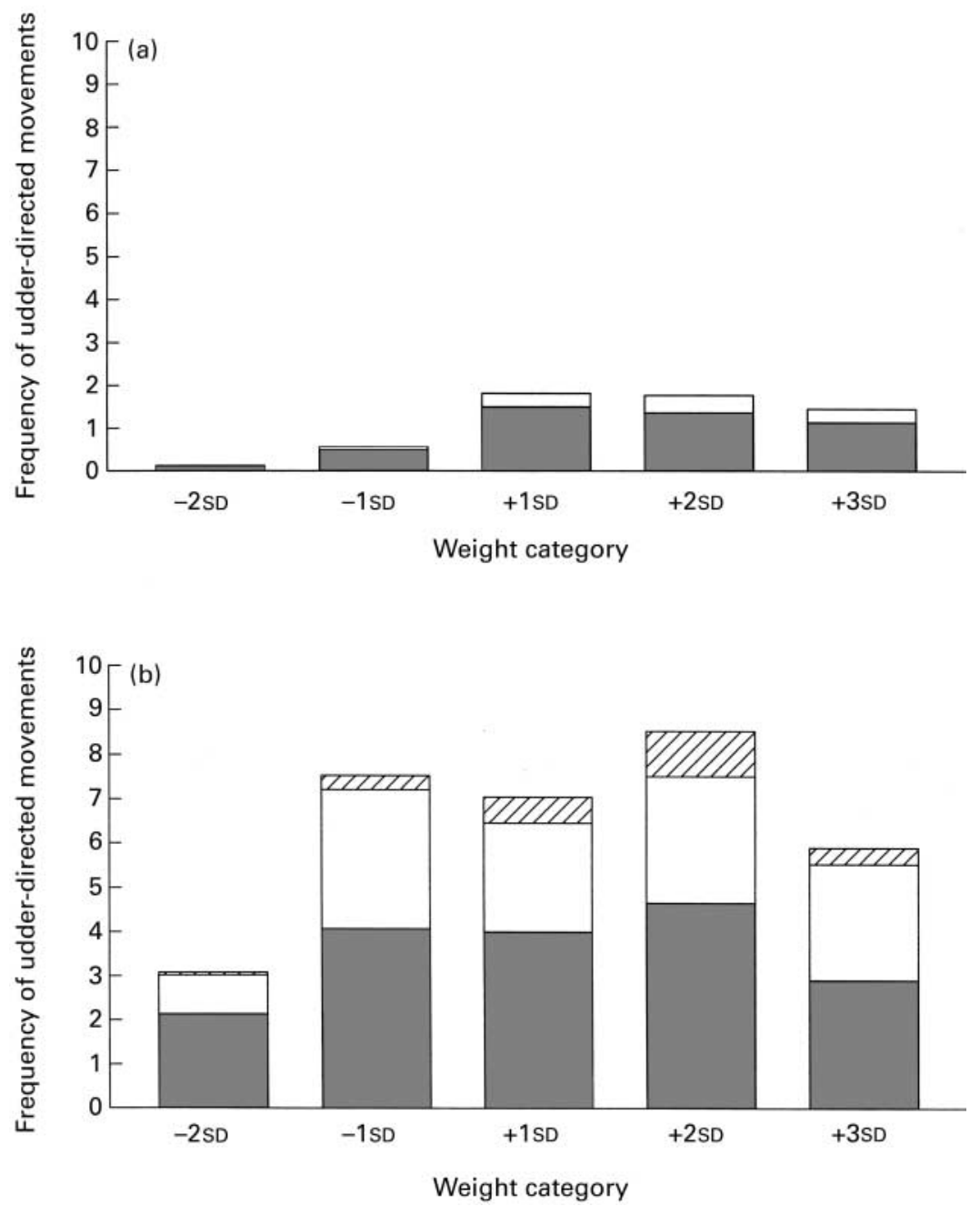

Fig. 4. Effect of weight category of lambs on frequency of udder-directed movements and the types of movements made by lambs in (a), the first $30 \mathrm{~min}$ after birth and (b), the subsequent $90 \mathrm{~min}$. $\square$, Lamb reaches udder; $\square$, lamb attempts to suck; 四, lamb sucks successfully. For details of diets and procedures, see Table 1 and p. 124. For division of lambs into birth weight categories see p. 124-125. All lambs weighing $\geq-3$ SD below mean birth-weight were stillborn.

milestones. However, lamb birth-weight had a significant effect on the latency to perform nearly all neonatal behaviours (Table 3). In general, very-low-birth-weight lambs ( $\geq 2$ SD below the mean) were slower than all other lambs. Low-birth-weight lambs $(\geq 1 \mathrm{SD}$ below the mean birth weight) were slower than lambs that weighed greater than the mean value. The amount of assistance required to deliver the lamb also had a significant effect on the early behaviours of the lamb but not thereafter (latency to reach knees: no assistance 2.33 (95\% CI 1.83, 2.96), partial assistance 3.54 (95\% CI $2.78,4.50)$, manual delivery 3.90 (95\% CI 3.06, 4.96) min, $P<0.05$ ). There were no significant effects of lamb sex or litter size on lamb behavioural development.

Lamb sucking behaviour. There were no direct effects of nutritional treatment on the sucking behaviour of the lamb. The frequency of lamb udder-directed movements (at the udder, attempting to suck and sucking successfully) is shown in Fig. 4. Heavier lambs had a significantly greater percentage of udder-directed movements that were sucking attempts than lighter lambs $(-2 \mathrm{SD} 3 \cdot 5$, -1 SD $7 \cdot 8,+1$ SD $15 \cdot 4,+2$ SD $20 \cdot 9,+3$ SD $20.4 \%, P<0 \cdot 05)$. In the subsequent $90 \mathrm{~min}$ period (Fig. 4(b)), lamb weight had a significant effect on all movements of the lamb to the udder $(P<0 \cdot 05)$. Body weight of the lamb also had a significant effect on the proportion of udder-directed movements that resulted in successful sucking $(-2 \mathrm{SD} 1.9,-1 \mathrm{SD}$ $3 \cdot 8,+1$ sD $7 \cdot 6,+2$ sD $11 \cdot 3,+3$ sD $6.0 \%, P<0 \cdot 01)$. There were no significant differences between treatment groups in ewe responses to lamb sucking behaviours.

\section{Ewe and lamb vocalisations}

Ewe vocalisations were classified as 'low-pitched' (the specific lambing vocalisation made by ewes to their lambs) or 'high-pitched' (characteristically distress vocalisations). There were no direct effects of nutritional treatment on ewe high- or low-pitched vocalisations. Litter 


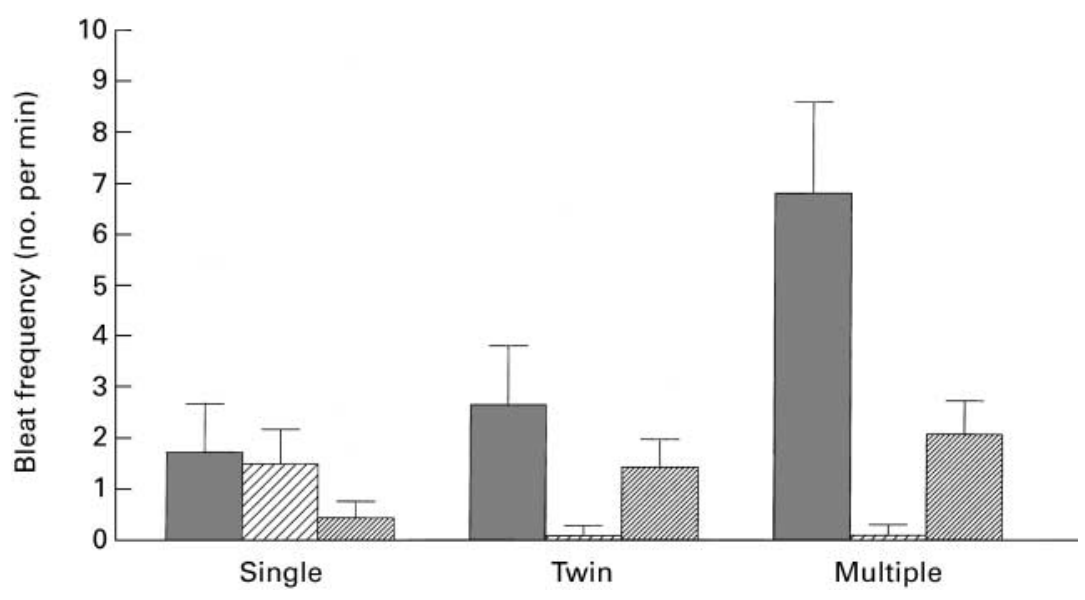

Fig. 5. Effect of lamb litter size on bleat frequency for single, twin and multiple litters. , Ewe low-pitched bleats; ewe high-pitched bleats; lamb bleats. For details of diets and procedures, see Table 1 and p. 124.

size and the amount of assistance required at delivery were the main effects on both ewe vocalisations. An increase in litter size caused a corresponding increase in low-pitched bleating $(P<0 \cdot 01)$, but a decrease in high-pitched bleating by the ewe (Fig. 5, $P<0 \cdot 001$ ). Ewes that required assistance at delivery had a lower frequency of low-pitched bleating than unassisted ewes (no assistance $5.34(95 \%$ CI 4.09, 6.75), partial assistance 3.32 (95\% CI 2.36, 4.46), manual delivery 2.02 (95\% CI $1.28,2.92)$ bleats per min, $P<0 \cdot 01$ ).

Lamb bleats were unaffected by maternal nutritional treatment. Lamb vocalisations were affected only by litter size: an increase in litter size caused an increase in lamb bleat frequency (Fig. 5, $P<0 \cdot 01$ ).

\section{Behaviour to 3 d postnatal}

There was no effect of nutritional treatment on the mean distance between the ewe and lamb, or on the proportion of observations where the ewe or lamb was standing. The main difference between the two treatments was in the time spent eating in the first $3 \mathrm{~d}$ of lactation, as $\mathrm{L}$ ewes were seen eating significantly more often than $\mathrm{H}$ ewes (H 9.11, L 25.31\% observations of SED 1.66, $P<0.001$ ). $\mathrm{H}$ ewes were more vocal than $\mathrm{L}$ ewes and this was significant for ewe low-pitched bleating ( $\mathrm{H} \mathrm{4.50,} \mathrm{L} \mathrm{2.61 \%} \mathrm{obser-}$ vations of SED 0.84, $P<0 \cdot 05)$. By contrast, $\mathrm{H}$ lambs tended to be less vocal than $\mathrm{L}$ lambs over the same period (H 1.55 (95\% CI 1.05, 2.15), L 2.57 (95\% CI 1.91, 3.33) percent observations, $P=0 \cdot 11)$. There was no effect of maternal gestational treatment on the frequency with which lambs were seen either sucking or playing. However, L lambs had a significantly greater frequency of performing exploratory behaviours (of both the pen fixtures and other animals) than $\mathrm{H}$ lambs (L 3.90, H $2.56 \%$ observations, SED $0.60, P<0 \cdot 05)$.

\section{Tests of maternal attachment}

Maternal behaviour score. $\mathrm{H}$ ewes were significantly more likely to receive high maternal behaviour scores (score 6: H 41.3, L 21.4\% ewes) and less likely to receive low scores (score 2 (no ewes received a score of 1 ): H 3.5, L $14.3 \%, \chi^{2} 9.74$, df $\left.4, P<0.05\right)$ than L ewes.

Maternal attachment score. H ewes were less likely to be assigned a low score (score 1 or 2: H 3.2, L 20.7\%) than $\mathrm{L}$ ewes and more likely to receive a high score (score 4: H 61.3 , L $37.9 \%, \chi^{2} 5.69$, df $2, P=0.058$ ).

Ewes that scored highly on the first test of maternal attachment (maternal behaviour score) also received high scores for the maternal attachment score $(r 0 \cdot 34, n 56$, $P<0 \cdot 05)$.

\section{Discussion}

Poor lamb survival following maternal undernutrition during pregnancy is a probable consequence of a low lamb birth-weight, leading to impaired thermoregulatory ability and reduced maternal lactation. The present study demonstrates that even a moderate level of maternal undernutrition in pregnancy can have deleterious consequences for the expression of maternal behaviour in the sheep, which may compound the reduced survivability of the lamb. Furthermore, the effect of maternal undernutrition on lamb birth-weight may also impair lamb neonatal behaviours leading to a delay in sucking.

\section{Maternal response at parturition to undernutrition in pregnancy}

The level of undernutrition used in the present study reduced maternal weight-gain during pregnancy and resulted in a net loss of $6.7 \%$ maternal body weight in the $\mathrm{L}$ ewes. This is considerably less than values of up to $25 \%$ weight loss reported in Cheviot sheep wintered outdoors (Thomson \& Thomson, 1949). However, this level of nutritional restriction did require the ewes in our present study to mobilise body reserves as shown by both their loss of backfat over pregnancy and the increased $\beta$-hydroxybutyrate concentration in the $\mathrm{L}$ ewes from week 16 of gestation onwards.

Maternal nutritional restriction also had an effect on 
plasma steroid hormone concentrations in the later stages of pregnancy. Although the effect of undernutrition on plasma oestradiol was relatively short-lived, L ewes had elevated plasma progesterone concentrations over the last third of gestation in comparison with the $\mathrm{H}$ ewes. A similar inverse relationship between nutrition level and plasma progesterone concentration has been reported previously in sheep and cattle (Gauthier et al. 1983; Vincent et al. 1985; Hall et al. 1992; O’Doherty \& Crosby, 1996). A low feed intake is also associated with a delay in the postpartum decline in plasma progesterone (Mellor et al. 1987). Plasma progesterone concentration is negatively correlated with colostrum and milk yield (Hall et al. 1992; O'Doherty \& Crosby, 1996) and postpartum delay in lactogenesis in under-fed ewes is associated with a delayed decline in progesterone (Mellor et al. 1987). These results suggest that, in our present study, the L ewes with elevated plasma progesterone are likely to have had impaired colostrum and milk production.

In addition to their roles in preparing the maternal body for birth and lactation, the steroid hormones also play an important function in the onset of maternal behaviour. In sheep, oestradiol and progesterone play an essential priming role in the onset of maternal behaviour (for reviews, see Keverne, 1988; Keverne \& Kendrick, 1994). In the rat, the onset of maternal behaviour is also related to temporal changes in the relative concentrations of oestrogen and progesterone, essentially an increase in oestradiol and a decline in progesterone (Doerr et al. 1981; Rosenblatt, 1994). These temporal effects have not been investigated in sheep. In both rats and sheep, maternal behaviour is then induced by the central release of oxytocin (Fahrbach et al. 1984; Keverne \& Kendrick, 1992). In sheep, both progesterone and oestrogen promote the synthesis of oxytocin mRNA in areas of the brain implicated in maternal behaviour (Broad et al. 1993). In behavioural studies in sheep and rats, high oestradiol (Pryce et al. 1988; Shipka \& Ford, 1991; Dwyer et al. 1999) and a high oestradiol: progesterone value (Pryce et al. 1993; Dwyer et al. 1999) in late gestation is correlated with the expression of maternal behaviour. The effects of undernutrition in elevating plasma progesterone in late gestation and reducing the oestradiol: progesterone value, seen in the present study, may be responsible for differences in maternal behaviour between the $\mathrm{L}$ and $\mathrm{H}$ ewes.

Despite the relatively mild nutritional restriction in comparison with what ewes may experience during the winter, $\mathrm{L}$ ewes did show deficits in maternal care in comparison with the $\mathrm{H}$ ewes. There was no apparent difference in the timing of onset of maternal care; however $\mathrm{L}$ ewes did not spend as much time grooming the lamb as $\mathrm{H}$ ewes immediately after the birth of their lambs. This may have been due to the competing motivations to eat and to care for their lambs, as the $\mathrm{L}$ ewes spent more time eating after the birth of their lambs than $\mathrm{H}$ ewes. In addition to the direct effects of undernutrition on maternal care, there were several effects of nutrition level on the parturition process that have responses correlated with reduced expression of maternal care. $\mathrm{L}$ ewes had a longer interval between the birth of the first and second twins, as has been reported previously (Thomson \& Thomson, 1949), which is known to reduce total grooming attention in ewes (Dwyer \& Lawrence, 1998) as was the case in the present study. In addition, L ewes had a higher incidence of malpresented lambs and required more assistance with lamb delivery. Assistance at delivery was shown to reduce ewe low-pitched bleats, a specific vocalisation associated with maternal care (Shillito, 1972; Dwyer et al. 1998) that is thought to play a role in ewe-lamb bond formation (Nowak, 1996). Thus, undernutrition affected the expression of maternal care directly through a reduction in maternal grooming behaviour, and indirectly by prolonging the parturition process.

\section{Effects of maternal undernutrition on neonate behaviours}

Maternal nutritional restriction during pregnancy caused a small but significant $(P<0 \cdot 05)$ reduction in mean lamb birth-weight of $9 \%$ when compared with well-fed ewes. Although there were no direct effects of maternal nutritional treatment on lamb behaviour, lamb birth-weight was shown to have a significant influence on neonatal lamb behavioural development in the first few hours after birth. In general, low-birth-weight lambs had a slower progression to standing and sucking than heavier lambs. Standing and sucking quickly have been shown to be related to improved survival rates in lambs (Owens et al. 1985; Cloete, 1993; Dwyer et al. 2001). This is related not only to the nutritional and immunological benefits of early colostrum ingestion, but also to the effects of sucking on lamb bonding to the ewe (Nowak et al. 1997). In addition to their slower development, low-birth-weight lambs appeared to lack co-ordination or the ability to accomplish successful sucking when compared with heavier lambs, as shown by the lower proportion of sucking attempts that resulted in successful sucking. Impaired neuromotor development has been demonstrated in prenatally undernourished young in other species (e.g. Gramsbergen \& Westerga, 1992), suggesting that undernutrition impairs both vigour and the ability to carry out complex behaviours. This may be due to the effects of undernutrition on the development and complexity of brain structures, leading to reductions in cell numbers and myelination of axons (for reviews, see Morgane et al. 1993; Rees et al. 1998; Dauncey \& Bicknell, 1999; Mallard et al. 2000).

Lambs born to L mothers had a higher incidence of malpresentation than $\mathrm{H}$ lambs, and tended to require greater assistance at delivery, despite their lower birth-weight. This supports our previous conclusions that birth difficulty is not simply related to lamb birth-weight (Dwyer et al. 1996), but may reflect events occurring prenatally, particularly those that may restrict fetal movement in utero such as restrictions in uterine growth or the volume of amniotic fluid. Requiring assistance at delivery caused a delay in the expression of early lamb behaviours in the present study and previously (Dwyer et al. 1996), and reduced the number of udder-directed movements made by the lambs. Thus, maternal undernutrition during gestation had an indirect effect on the early expression of neonatal lamb behaviours as well as effects on lamb birth-weight. 


\section{Effects on the development of the ewe-lamb relationship}

Over the first $3 \mathrm{~d}$ of the developing ewe-lamb relationship there were few behavioural differences between $\mathrm{H}$ and $\mathrm{L}$ ewes although $\mathrm{H}$ ewes made low-pitched vocalisations to their lambs more frequently than L ewes. As low-pitched bleating is an expression of maternal care or concern (Dwyer et al. 1998), this suggests that the effects of nutrition on the initial expression of maternal behaviour may persist over the early postnatal period. L ewes were also found to spend significantly more time eating than $\mathrm{H}$ ewes. Lactation is an energetically expensive process (e.g. Reynolds \& Tyrrell, 1990); thus, L ewes may have needed to spend more time eating to meet the requirements of lactation as they had less body reserves to draw on than the $\mathrm{H}$ ewes. In addition, L ewes appeared to be more foodmotivated than $\mathrm{H}$ ewes. This increased food-motivation is a possible explanation for the increased likelihood of undernourished Merino ewes moving away from the birth-site soon after birth (Putu et al. 1988).

There were also few behavioural differences between $\mathrm{H}$ and $\mathrm{L}$ lambs in the first $3 \mathrm{~d}$ of postnatal life, although $\mathrm{L}$ lambs were seen performing investigatory behaviours more often than $\mathrm{H}$ lambs. In addition, $\mathrm{L}$ lambs tended to bleat more frequently than $\mathrm{H}$ lambs. As suggested earlier, although not measured in the present study, it is likely that the L ewes had reduced udder development and lactation rates in comparison with the $\mathrm{H}$ ewes. The increased investigatory behaviour of the $\mathrm{L}$ lambs, particularly of other ewes, may be a consequence of lower intake or poorer quality of milk ingested by these lambs. Neonate vocal behaviour has been suggested to function as an expression of degree of need (Brunelli et al. 1994; Weary \& Fraser, 1995) and, in lambs, bleat rate is inversely related to the amount of maternal care received (Dwyer et al. 1998). Increased lamb vocalisations in the L lambs may, therefore, be an expression of reduced maternal care by the $\mathrm{L}$ ewes.

In tests of ewe attachment to her lamb at both 24 and $72 \mathrm{~h}$ after birth, L ewes were more likely to receive low scores (reflecting maternal disinterest in her lambs) than $\mathrm{H}$ ewes. This may be a result of inadequate bond formation between the ewe and her lambs at the initiation of maternal behaviour, mediated by reduced grooming behaviour. However, as sucking and milk ingestion play a fundamental role in lamb bonding to the ewe (Nowak et al. 1997) and in the maintenance of maternal behaviour (Rosenblatt \& Siegel, 1981), lower milk production in the $\mathrm{L}$ ewes may influence the quality of the relationship formed by the lamb to the ewe, and interfere with the maintenance of maternal behaviour.

\section{Conclusions and implications}

This present study has demonstrated that even a moderate reduction in maternal nutritional intake in primiparous ewes can result in a quantitative reduction in the expression of maternal behaviour at parturition. This suggests that more extreme undernutrition, as may be experienced by hill ewes under normal farm conditions, is likely to cause larger deficits in maternal behaviour. Tests of ewe-lamb bonding demonstrated a weaker relationship between ewe and lamb in undernourished mothers, although whether this was related to the onset or maintenance of maternal behaviour could not be disentangled in the present study. As lamb survival is crucially dependent on the adequate expression of maternal care from the ewe (for review, see Nowak et al. 2000), any impairment in maternal care will increase the probability that the lamb will not survive, in addition to compromised lamb survival through low birth-weight or poor maternal lactation. A possible mechanism by which maternal undernutrition can influence the expression of maternal behaviour is the elevation of plasma progesterone in mid to late gestation, and the lower oestradiol: progesterone value in L ewes in comparison with $\mathrm{H}$ animals.

These present studies were carried out in primiparous ewes, which may be more susceptible to nutritional influences on maternal care than multiparous ewes. Primiparous ewes are known to perform less well as mothers in comparison with multiparous ewes (O'Connor et al. 1992; Dwyer \& Lawrence, 2000) and are more sensitive to manipulations of both external and internal cues than multiparous ewes (e.g. presence of olfactory cues: Lévy \& Poindron, 1987; Lévy et al. 1995; effects of progesterone, oestrogen, opioids and oxytocin: Kendrick \& Keverne, 1991; Keverne \& Kendrick, 1991). Thus, multiparous ewes may have a more robust maternal response to moderate undernutrition than primiparous ewes. However, these studies were carried out on hill sheep, which have been selected primarily for their ability to survive and reproduce under unfavourable conditions. It is likely that these animals may have a lesser response to undernutrition than breeds selected to perform under more favourable conditions, which are already known to show reduced maternal care under improved conditions (Dwyer \& Lawrence, 1998).

Finally, although the present study did not show an effect of maternal nutritional treatment on the expression of neonatal lamb behaviours, the effect of treatment produced only a small average difference in birth weight. In the present study, however, lamb neonatal progress was affected by birth weight with low-birth-weight lambs taking longer to perform all behaviours than heavier lambs. This delayed development is likely to be exacerbated by more severe undernutrition and is known to be related to lamb survival (Owens et al. 1985; Cloete, 1993; Dwyer et al. 2001). Furthermore, as the present experiment was carried out indoors, the lambs were protected from the effects of precipitation and wind chill. In outdoor hill conditions, even small delays in standing and sucking may have more severe consequences for lamb survival.

\section{Acknowledgements}

We thank the following: Jack FitzSimons, Mark Ramsay and David Wallace for animal husbandry; Sheena Calvert, Julie Stevenson, Jenny Ogg, Jacqui Mann and Anna Johnson for technical assistance at lambing time; Fiona 
Gebbie and Karen Mackie for the oestradiol and progesterone assays. This study was supported by the Scottish Executive Rural Affairs Department and the Department for Environment, Food and Rural Affairs.

\section{References}

Agriculture and Food Research Council (1993) Energy and Protein Requirements of Ruminants. Wallingford, Oxon.: CAB International.

Bizelis JA, Charismiadou MA \& Rogdakis E (2000) Metabolic changes during the perinatal period in dairy sheep in relation to level of nutrition and breed. II Early lactation. Journal of Animal Physiology and Animal Nutrition 84, 73-84.

Broad KD, Kendrick KM, Sirinathsinghji DJS \& Keverne EB (1993) Changes in oxytocin immunoreactivity and mRNA expression in the sheep brain during pregnancy, parturition and lactation and in response to oestrogen and progesterone. Journal of Neuroendocrinology 5, 435-444.

Brunelli SA, Shair HN \& Hofer MA (1994) Hypothermic vocalisations of rat pups (Rattus norvegicus) elicit and direct maternal search behaviour. Journal of Comparative Psychology 108, 298-303.

Budge H, Bispham J, Dandrea J, Evans E, Heasman L, Ingleton PM, Sullivan C, Wilson V, Stephenson T \& Symonds ME (2000) Effect of maternal nutrition on brown adipose tissue and its prolactin receptor status in the fetal lamb. Pediatric Research 47, 781-786.

Charismiadou MA, Bizelis JA \& Rogdakis E (2000) Metabolic changes during the perinatal period in dairy sheep in relation to level of nutrition and breed. I Late pregnancy. Journal of Animal Physiology and Animal Nutrition 84, 61-72.

Clarke L, Yakubu DP \& Symonds ME (1997) Influence of maternal bodyweight on size, conformation and survival of newborn lambs. Reproduction, Fertility and Development 9, 509-514.

Cloete SWP (1993) Observations on neonatal progress of Dormer and South African Mutton Merino lambs. South African Journal of Animal Science 23, 38-42.

Dauncey MJ \& Bicknell RJ (1999) Nutrition and neurodevelopment: mechanisms of developmental dysfunction and disease in later life. Nutrition Research Reviews 12, 231-253.

Doerr HK, Siegel HI \& Rosenblatt JS (1981) Effects of progesterone withdrawal and estrogen on maternal behaviour in nulliparous rats. Behavioural and Neural Biology 32, 35-44.

Dwyer CM, Dingwall WS \& Lawrence AB (1999) Physiological correlates of mother-offspring behaviour in sheep: A factor analysis. Physiology and Behavior 67, 443-454.

Dwyer CM \& Lawrence AB (1998) Variability in the in expression of maternal behaviour in primiparous sheep: Effects of genotype and litter size. Applied Animal Behaviour Science 58, 311-330.

Dwyer CM \& Lawrence AB (2000) Maternal behaviour in domestic sheep (Ovis aries): Constancy and change with maternal experience. Behaviour 137, 1391-1413.

Dwyer CM, Lawrence AB \& Bishop SC (2001) The effects of selection for lean tissue content on maternal and neonatal lamb behaviours in Scottish Blackface sheep. Animal Science 72, 555-571.

Dwyer CM, Lawrence AB, Brown HE \& Simm G (1996) The effect of ewe and lamb genotype on gestation length, lambing ease and neonatal behaviour of lambs. Reproduction, Fertility and Development 8, 1123-1129.

Dwyer CM, McLean KA, Deans LA, Chirnside J, Calvert SK \& Lawrence AB (1998) Vocalisations between mother and young in the sheep: Effects of breed and maternal experience. Applied Animal Behaviour Science 58, 105-119.

Fahrbach SE, Morrell JI \& Pfaff DW (1984) Oxytocin induction of short-latency maternal behaviour in nulliparous, estrogenprimed female rats. Hormones and Behavior 18, 267-286.

Gauthier D, Terqui M \& Mauleon P (1983) Influence of nutrition on pre-partum plasma levels of progesterone and total oestrogens and postpartum levels of luteinising hormone and follicle-stimulating hormone in suckling cattle. Animal Production 37, 89-96.

Gramsbergen A \& Westerga J (1992) Locomotor development in undernourished rats. Behavioural Brain Research 48, $57-64$.

Hall DG, Holst PJ \& Shutt DA (1992) The effect of nutritional supplements in late pregnancy on ewe colostrum production, plasma progesterone and IGF-1 concentrations. Australian Journal of Agricultural Research 43, 325-337.

Hinch GN, Lynch JJ, Nolan JV, Leng RA, Bindon BM \& Piper LR (1996) Supplementation of high fecundity Border Leicester $\times$ Merino ewes with a high protein feed: its effect on lamb survival. Australian Journal of Experimental Agriculture 36 129-136.

Kendrick KM \& Keverne EB (1991) Importance of progesterone and estrogen priming for the induction of maternal behavior by vaginocervical stimulation in sheep: Effects of maternal experience. Physiology and Behavior 49, 745-750.

Keverne EB (1988) Central mechanisms underlying the neural and neuroendocrine determinants of maternal behaviour. Psychoneuroendocrinology 13, 127-141.

Keverne EB \& Kendrick KM (1991) Morphine and corticotrophin-releasing factor potentiate maternal acceptance in multiparous ewes after vaginocervical stimulation. Brain Research 540, 55-62.

Keverne EB \& Kendrick KM (1992) Oxytocin facilitation of maternal behaviour in sheep. Annals of the New York Academy of Sciences 652, 83-101.

Keverne EB \& Kendrick KM (1994) Maternal behaviour in sheep and its neuroendocrine regulation. Acta Paediatrica 83, 47-56.

Kleeman DO, Walker SK, Walkley JRW, Ponzoni RW, Smith DH, Grimson RJ \& Seamark RF (1993) Effect of nutrition during pregnancy on birth weight and lamb survival in FecB Booroola $\times$ South Australian Merino ewes. Animal Reproduction Science 31, 213-224.

Langenau EE \& Lerg JM (1976) The effects of winter nutritional stress on maternal and neonatal behavior in penned white-tailed deer. Applied Animal Ethology 2, 207-223.

Lévy F, Locatelli A, Piketty V, Tillet Y \& Poindron P (1995) Involvement of the main but not the accessory olfactory system in maternal behaviour of primiparous and multiparous ewes. Physiology and Behavior 57, 97-104.

Lévy F \& Poindron P (1987) The importance of amniotic fluids for the establishment of maternal behaviour in experienced and inexperienced ewes. Animal Behaviour 35, 1188-1192.

McDonald IW (1962) Ewe fertility and neonatal lamb mortality. New Zealand Veterinary Journal 10, 45-52.

McNeilly AS \& Fraser HM (1987) Effect of gonadotrophinreleasing hormone agonist induced suppression of $\mathrm{LH}$ and FSH on follicle growth and corpus luteum function in the ewe. Journal of Endocinology 115, 273-282.

Mallard C, Loeliger M, Copolov D \& Rees S (2000) Reduced number of neurons in the hippocampus and the cerebellum in the postnatal guinea-pig following intrauterine growthrestriction. Neuroscience 100, 327-333.

Mann GE, Lamming GE \& Fray MD (1995) Plasma oestradiol and progesterone during early pregnancy in the cow and the effects of treatment with buserelin. Animal Reproduction Science 37, 121-131. 
Mellor DJ (1983) Nutritional and placental determinants of foetal growth rate in sheep and consequences for the new born lamb. British Veterinary Journal 139, 307-324.

Mellor DJ, Flint DJ, Vernon RG \& Forsyth IA (1987) Relationships between plasma hormone concentrations, udder development and the production of early mammary secretions in twin-bearing ewes on different planes of nutrition. Quarterly Journal of Experimental Physiology and Cognate Medical Sciences 72, 345-356.

Mellor DJ \& Murray L (1985) Effects of maternal nutrition on udder development during late pregnancy and on colostrum production in Scottish Blackface ewes with twin lambs. Research in Veterinary Science 39, 230-234.

Moore RW, Millar CM \& Lynch PR (1986) The effects of prenatal nutrition and type of birth and rearing of lambs on vigour, temperature and weight at birth, and weight and survi$\mathrm{val}$ at weaning. Proceedings of the New Zealand Society of Animal Production 46, 259-262.

Morgane PJ, Austin-LaFrance R, Bronzino J, Tonkiss J, Diaz-Cintra S, Cintra L, Kemper T \& Galler JR (1993) Prenatal malnutrition and development of the brain. Neuroscience and Biobehavioural Reviews 17, 91-128.

Noldus LPJJ, Trienes RJH, Hendriksen AHM, Jansen H \& Jansen RG (2000) The Observer Video-Pro: New software for the collection, management, and presentation of time-structured data from videotapes and digital media files. Behavior Research Methods, Instruments, and Computers 32, 197-206.

Nowak R (1996) Neonatal survival: contributions from behavioural studies in sheep. Applied Animal Behaviour Science 49, 61-72.

Nowak R, Murphy TM, Lindsay DR, Alster P, Andersson R \& Uvnäs-Moberg K (1997) Development of a preferential relationship with the mother: importance of the sucking activity. Physiology and Behavior 62, 681-688.

Nowak R, Porter RH, Lévy F, Orgeur P \& Schaal B (2000) Role of mother-young interactions in the survival of offspring in domestic mammals. Reviews of Reproduction 5, 153-163.

O'Connor CE, Jay NP, Nicol AM \& Beatson PR (1985) Ewe maternal behaviour score and lamb survival. Proceedings of the New Zealand Society for Animal Production 45, 159-162.

O'Connor CE, Lawrence AB \& Wood-Gush DGM (1992) Influence of litter size and parity on maternal behaviour at parturition in Scottish Blackface sheep. Applied Animal Behaviour Science 33, 345-355.

O'Doherty JV \& Crosby TF (1996) The effect of diet in late pregnancy on progesterone concentration and colostrum yield in ewes. Theriogenology 46, 233-241.

Owens JL, Bindon BM, Edey TN \& Piper LR (1985) Behaviour at parturition and lamb survival of Booroola Merino sheep. Livestock Production Science 13, 359-372.

Patterson HD \& Thompson R (1971) Recovery of inter-block information when block sizes are unequal. Biometrika 58, 545-554.

Pryce CR, Abbott DH, Hodges JK \& Martin RD (1988) Maternal behaviour is related to prepartum urinary oestradiol levels in red-bellied tamarin monkeys. Physiology and Behaviour 44, $717-726$.
Pryce CR, Dobeli M \& Martin RD (1993) Effects of sex steroids on maternal motivation in the common marmoset (Callithrix jacchus ) - Development and application of an operant system with maternal reinforcement. Journal of Comparative Psychology 107, 99-115.

Putu IG, Poindron P \& Lindsay DR (1988) A high level of nutrition during late pregnancy improves subsequent maternal behaviour in Merino ewes. Proceedings of the Australian Society of Animal Production 17, 294-297.

Rees S, Mallard C, Breen S, Stringer M, Cock M \& Harding R (1998) Fetal brain injury following prolonged hypoxemia and placental insufficiency: A review. Comparative Biochemistry and Physiology 119A, 653-660.

Reynolds CK \& Tyrell HF (1990) Energy metabolism in lactating and dry beef cows. Journal of Animal Science 68, Suppl. 1, 523.

Robinson JJ \& Aitken RP (1985) Effects of nutrition on prenatal growth and implications for perinatal survival in lambs. In Factors Affecting the Survival of Newborn Lambs. Seminar in CEC Programme of Co-ordination of Agricultural Research, pp. 177-189 [G Alexander, JD Barker and J Slee, editors]. Brussels: Commission of European Communities.

Robinson JJ, McEvoy TG \& Sinclair KD (1999) Nutritional effects on foetal growth. Animal Science 68, 315-331.

Rosenblatt JS (1994) Psychobiology of maternal behaviour Contributions to the clinical understanding of maternal behaviour among humans. Acta Paediatrica 83, 3-8.

Rosenblatt JS \& Siegel HI (1981) Factors governing the onset and maintenance of maternal behaviour among nonprimate mammals. In Parental Care in Mammals, pp. 13-76 [DJ Gubernick and PH Klopfer, editors]. New York: Plenum Press

Russel AJF, Gunn RG \& Doney JM (1968) Components of weight loss in pregnant hill ewes during winter. Animal Production 10, 43-51.

Scales GH, Burton RN \& Moss RA (1986) Lamb mortality, birthweight and nutrition in late pregnancy. New Zealand Journal of Agricultural Research 29, 75-82.

Shillito EE (1972) Vocalisation in sheep. Journal of Physiology 226, 45P-46P.

Shipka MP \& Ford SP (1991) Relationship of circulating oestrogen and progesterone concentrations during later pregnancy and the onset phase of maternal behaviour in the ewe. Applied Animal Behaviour Science 31, 91-99.

Thomson AM \& Thomson W (1949) Lambing in relation to the diet of the pregnant ewe. British Journal of Nutrition 2, 290-305.

Vincent IC, Williams HL \& Hill R (1985) The influence of a lownutrient intake after mating on gestation and perinatal survival of lambs. British Veterinary Journal 141, 611-617.

Waterhouse A, Roger LC \& Ashworth SA (1992) Reducing lamb mortality in hill sheep. In Neonatal Survival and Growth. Occasional Publication of British Society of Animal Production no. 10, pp. 43-50 [MA Varley, PEV Williams and TLJ Lawrence, editors]. Midlothian, UK: British Society for Animal Production.

Weary DM \& Fraser D (1995) Calling by domestic piglets: reliable signals of need? Animal Behaviour 50, 1047-1055. 